\title{
ESTUDO DA INFLUÊNCIA DO DIÂMETRO DE UNDERFLOW E DO COMPRIMENTO DE VORTEX FINDER NO HIDROCICLONE OTIMIZADO HCOT1
}

\author{
Y. N. KYRIAKIDIS, M. A. S. BARROZO e L. G. M. VIEIRA \\ Universidade Federal de Uberlândia, Faculdade de Engenharia Química \\ E-mail: luizgustavo@feq.ufu.br
}

\begin{abstract}
RESUMO - Os hidrociclones são equipamentos cônico-cilíndricos destinados à separação sólido-líquido e líquido-líquido que utilizam o campo centrífugo gerado por sua alimentação tangencial para promover a separação entre duas fases. De acordo com a finalidade almejada pelo usuário (concentração ou classificação), é possível potencializar o desempenho dos hidrociclones mediante alterações em suas variáveis operacionais. Dessa forma, com interesse em aprimorar uma geometria já otimizada para altas eficiências de separação, HCOT1, cujas variáveis de projeto foram determinadas por Silva (2012), o presente trabalho estudou como a variação das dimensões do diâmetro de underflow e do comprimento de vortex finder influenciou a eficiência de separação, a capacidade de processamento, a razão de líquido, o gasto energético e o diâmetro de corte reduzido do hidrociclone HCOT1. Superfícies de resposta foram levantadas a partir de regressões múltiplas e concluiu-se que tais variáveis ditas operacionais afetam diretamente as variáveis calculadas, possuindo um comportamento de resposta não necessariamente linear entre os parâmetros estudados.
\end{abstract}

\section{INTRODUÇÃO}

Os hidrociclones são equipamentos cuja finalidade é a separação sólido-líquido ou líquidolíquido em campo centrífugo, podendo ser empregados com o intuito de classificar partículas ou concentrar uma das correntes, com o propósito de se recuperar uma das fases. São equipamentos de fácil construção e manutenção, com custo operacional reduzido, por esse motivo são largamente utilizados no setor industrial.

Um hidrociclone geralmente é constituído por um cilindro maciço que possui um duto de entrada tangencial ao mesmo, de forma a promover um escoamento em campo centrífugo, o qual é responsável pela separação das fases. Ainda na parte superior do cilindro, encontra-se um pequeno duto que adentra em parte de sua estrutura, chamado vortex finder, o qual possibilita a saída de uma parcela da mistura pelo orifício de overflow. O cilindro do hidrociclone é acoplado a um tronco de cone, também maciço, que gera uma restrição ao escoamento até que a suspensão possa ser descarregada no orifício de underflow. A Figura 1 ilustra um esquema representativo do equipamento. 


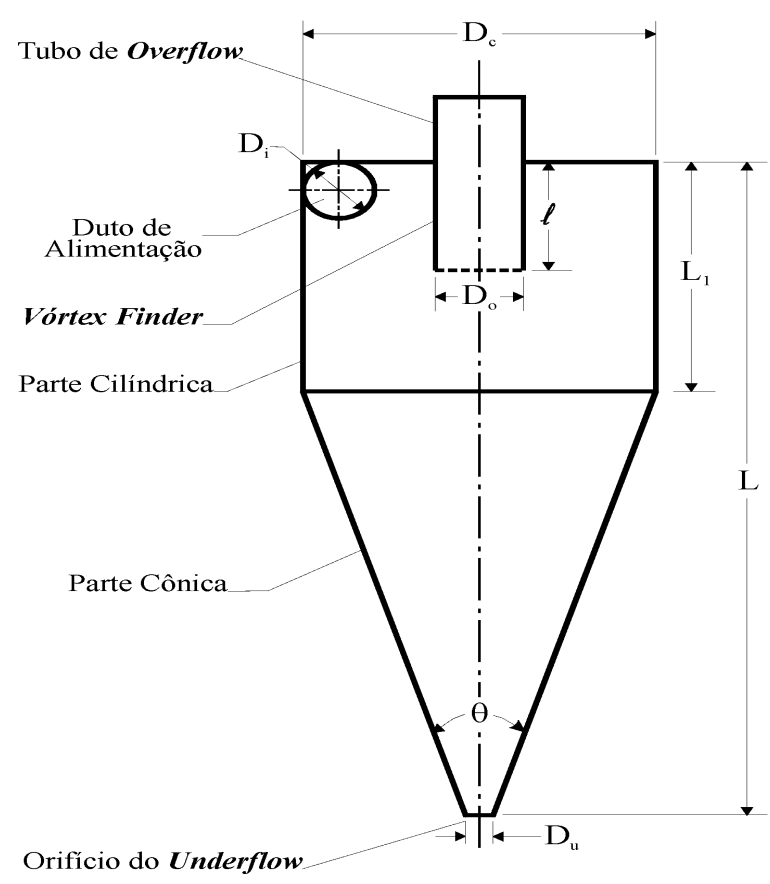

Figura 1 - Vista lateral das partes constituintes de um hidrociclone.

Para que se alcance o propósito de classificar ou concentrar a corrente de alimentação, existem vários tipos de famílias de hidrociclones, cuja principal característica é possuir relações geométricas específicas com o diâmetro da parte cilíndrica. As famílias convencionais são amplamente descritas na literatura e outras famílias são desenvolvidas especialmente a atender certas demandas industriais.

Nesse contexto, a Faculdade de Engenharia Química da Universidade Federal de Uberlândia (FEQUI/UFU) sempre se mostrou dedicada a estudos relacionados à separação de particulados, visto que a localização geográfica da Universidade favorece o estudo do fenômeno de hidrociclonagem. Na região do Triângulo Mineiro e parte do interior de Goiás há uma elevada demanda destes separadores, especialmente na área mineral e metalúrgica. Posto isso, um dos primeiros trabalhos de otimização da FEQUI/UFU englobando as dimensões geométricas das principais famílias de hidrociclones utilizadas no meio industrial foi feito por Vieira (2006). Nesse estudo, por intermédio de um planejamento composto central, Vieira (2006) deu origem a 25 geometrias de hidrociclones não convencionais a partir das famílias clássicas e notou que era possível obter um equipamento que oferecesse alta eficiência de separação a um baixo custo energético.

A fim de se aprimorar o processo de hidrociclonagem na separação sólido-líquido, o trabalho de Vieira (2006) instigou vários outros pesquisadores a darem continuidade ao estudo dos hidrociclones. Um deles foi Silva (2012) que, a partir de algoritmos de otimização, foi capaz de encontrar um hidrociclone que promovesse uma maior eficiência de separação a um menor custo energético, para um número máximo do adimensional de Euler pré-definido em sua região de busca, a qual incluía diversas geometrias de hidrociclones analisadas nas faixas experimentais estudadas por Vieira (2006). A esse hidrociclone otimizado foi dado o nome de HCOT1, pois foi o primeiro caso de otimização dentre os três estudados por Silva (2012). 
O hidrociclone HCOT1 possui suas dimensões de projeto definidas conforme a Tabela 1. No caso da otimização, foram levadas em consideração as relações geométricas das variáveis de projeto pelo diâmetro da parte cilíndrica $(D c)$, o qual foi fixado em $3,00 \cdot 10^{-2} \mathrm{~m}$. As variáveis de projeto em questão foram: diâmetro da alimentação $(D i)$, diâmetro de overflow $(D o)$, comprimento total $(L)$ e ângulo do tronco de cone $(\theta)$. Já as variáveis operacionais comprimento de vortex finder $(\ell)$ e diâmetro de underflow $(\mathrm{Du})$ foram mantidas constantes e respectivamente iguais a $1,20.10^{-2} \mathrm{~m}$ e $5,00.10^{-3} \mathrm{~m}$.

Tabela 1 - Dimensões das variáveis de projeto otimizadas para HCOT1

\begin{tabular}{lc} 
Diâmetro da alimentação & $7,80.10^{-3} \mathrm{~m}$ \\
\hline Diâmetro do duto de overflow & $5,70.10^{-3} \mathrm{~m}$ \\
\hline Comprimento total & $1,69.10^{-1} \mathrm{~m}$ \\
\hline Comprimento da parte cilíndrica & $1,00.10^{-2} \mathrm{~m}$ \\
\hline Comprimento do tronco de cone & $1,59.10^{-1} \mathrm{~m}$ \\
\hline Ângulo do tronco de cone & $9^{\circ}$
\end{tabular}

Dessa forma, o objetivo do presente trabalho foi estudar como a variação das dimensões $D u$ e do $\ell$ pode influenciar a eficiência de separação $(\eta$ ), a capacidade de processamento (vazão de alimentação), a razão de líquido $(R l)$, o gasto energético (inferido pelo número de Euler) e o diâmetro de corte reduzido $\left(d_{50}^{\prime}\right)$ do hidrociclone de geometria HCOT1.

\section{MATERIAIS E MÉTODOS}

A partir das dimensões utilizadas por Silva (2012), foi feito um planejamento fatorial em três níveis para as variáveis analisadas resultando em nove geometrias de hidrociclones. Foi determinado que o diâmetro de underflow $(D u)$ seria avaliado numa faixa entre $3,00.10^{-3} \mathrm{~m} \mathrm{e} 5,00.10^{-3} \mathrm{~m}$, com o limite superior igual ao empregado por Silva (2012) e com limite inferior acordado de forma a não obstruir o orifício. Da mesma maneira, o comprimento do vortex finder $(\ell)$ foi estabelecido entre $1,00.10^{-3} \mathrm{~m} \mathrm{e} 1,20.10^{-2} \mathrm{~m}$, com o limite superior idêntico àquele utilizado por Silva (2012) e com o limite inferior designado o menor possível, ainda proporcionando a existência do vortex finder.

Destarte, os fatores foram codificadas em X1 (comprimento do vortex finder) e $X 2$ (diâmetro do orifício de underflow) sendo que os níveis de cada variável com seus respectivos valores reais encontram-se na Tabela 2.

Tabela 2 - Níveis e dimensões correspondentes aos fatores $\ell$ e $D u$

\begin{tabular}{ccc}
\hline Nível & $\ell$ & $D u$ \\
\hline-1 & $1,00.10^{-3} \mathrm{~m}$ & $3,00.10^{-3} \mathrm{~m}$ \\
0 & $6,50.10^{-3} \mathrm{~m}$ & $4,00.10^{-3} \mathrm{~m}$ \\
+1 & $1,20.10^{-2} \mathrm{~m}$ & $5,00.10^{-3} \mathrm{~m}$
\end{tabular}


Ao que tange o material particulado, foi utilizado o chamado "quartzito", gentilmente cedido pela ANEX Mineração, cediada em Itabirito/MG. Esse material é formado predominantemente por dióxido de silício $\left(\mathrm{SiO}_{2}\right)$ e tem densidade igual a $2740 \mathrm{~kg} / \mathrm{m}^{3}$ (aferida em picnômetro a gás hélio).

A distribuição granulométrica do material segue o modelo RRB (Rosin-Rammlet-Bennet), para o qual os parâmetros $d_{63,2}$ e $n$ são respectivamente iguais a $12,89 \mu \mathrm{m}$ e 0,94 , para um diâmetro de partícula $d_{p}$ em $\mu \mathrm{m}$, sendo que o ajuste foi realizado com um coeficiente de correlação quadrática igual a 0,99 no software Statistica ${ }^{\circledR}$.

A suspensão utilizada durante os ensaios experimentais foi preparada de modo que sua concentração volumétrica de material particulado fosse igual a 1\%. Essa suspensão se mantinha homogeneizada em um tanque de armazenamento através de agitador mecânico e um par de chicanas, depois era bombeada através de uma bomba centrífuga através de tubulações, passando por um medidor de vazão tipo Coriolis e um manômetro de Bourdon digital até chegar ao hidrociclone.

O procedimento adotado foi o seguinte: fixava-se uma queda de pressão, registrava-se a temperatura da suspensão, a vazão mássica de alimentação $(W)$ do hidrociclone lida no display do medidor de vazão, aferia-se a vazão mássica da corrente de underflow $\left(W_{U}\right)$ através de técnicas gravimétricas, coletava-se amostras das correntes de alimentação e underflow, a fim de se determinar a concentração mássica das mesmas $\left(C_{W i}\right)$ e, por fim, coletava-se também das mesmas correntes alíquotas para testes de distribuição granulométrica utilizando-se técnica de difração a laser, através do equipamento Mastersizer Microplus da Malvern. As quedas de pressão utilizadas foram as mesmas de Silva (2012): 88, 118, 147 e $177 \mathrm{kPa}$. De posse dos dados coletados, foi possível então calcular a eficiência total de coleta, dada pela Equação 1.

$$
\eta=\frac{C_{W U} W_{U}}{C_{W A} W}
$$

Para calcular a razão de líquido $(R l)$, foi preciso determinar primeiramente a densidade de cada corrente $\left(\rho_{i}\right)$ através da Equação 2, para assim ser possível calcular a vazão volumétrica das correntes $\left(Q_{i}\right)$ por meio da Equação 3. Determinando-se a concentração volumétrica das correntes $\left(C_{v i}\right)$ pela Equação 4, torna-se viável o cálculo da razão de líquido $(R l)$ pela Equação 5.

$$
\begin{aligned}
& \rho_{i}=\frac{\rho}{1-C_{W i}\left(1-\frac{\rho}{\rho_{s}}\right)} \\
& Q_{i}=\frac{W_{i}}{\rho_{i}} \\
& C_{V i}=\frac{1}{\left[\frac{\rho_{s}}{\rho}\left(\frac{1}{C_{W i}}-1\right)+1\right]}
\end{aligned}
$$




$$
R l=\frac{Q_{U}\left(1-C_{V U}\right)}{Q\left(1-C_{V A}\right)}
$$

Com as dimensões do hidrociclone, as condições operacionais $(-\triangle P)$ e as variáveis já calculadas, estima-se o número adimensional de Euler, valendo-se da Equação 6.

$$
E u=\frac{-\Delta P}{\frac{\rho}{2}\left(\frac{4 Q}{\pi D c^{2}}\right)^{2}}
$$

Para o cálculo do diâmetro de corte reduzido $\left(d_{50}^{\prime}\right)$, que é o diâmetro da partícula que possui eficiência granulométrica reduzida igual a $50 \%$, se faz necessário a substituição da equação do modelo de distribuição granulométrica (RRB) na Equação 7, de cálculo de eficiência granulométrica $(G)$, e, em seguida, sua substituição na Equação 8, de cálculo de eficiência granulométrica reduzida $(G)$, resultando na Equação 9.

$$
\begin{aligned}
G & =\eta \frac{X_{U}}{X} \\
G^{\prime} & =\frac{G-R l}{1-R l} \\
0,5 & =\frac{\eta\left(\frac{\left(\frac{d_{p}}{d_{63,2 U}}\right)^{n_{U}} n_{U} \exp \left[-\left(\frac{d_{p}}{d_{63,2 U}}\right)^{n_{U}}\right]}{\left(\frac{d_{p}}{d_{63,2 A}}\right)^{n_{A}} n_{A} \exp \left[-\left(\frac{d_{p}}{d_{63,2 A}}\right)^{n_{A}}\right]}\right\}^{-R l}}{1-R l}
\end{aligned}
$$

Com todas variáveis calculadas, ainda foi possível determinar, por regressão múltipla, o valor da constante "K", única para cada família de hidrociclones, utilizando-se para isso a Equação 10, proposta por Massarani (1989).

$$
\frac{d_{50}^{\prime}}{D c}=K\left[\frac{\mu D c}{Q\left(\rho_{s}-\rho\right)}\right]^{1 / 2} \frac{1}{1+A R l} \exp \left(4,5 C_{V A}\right)
$$

\section{RESULTADOS E DISCUSSÕES}

A partir dos experimentos realizados, as variáveis mais relevantes para o processo de hidrociclonagem foram calculadas para cada queda de pressão. Em seguida, foi feita a média dos resultados para cada equipamento do planejamento fatorial, que encontra-se na Tabela 3.

Com base na Tabela 3, regressões múltiplas foram realizadas e superfícies de resposta foram calculadas. A Tabela 4 traz as funções que correlacionam cada variável calculada (resposta) com as variáveis operacionais estudadas e codificadas $(X 1$ e $X 2)$. Para as respostas $\eta$ e $Q$, as superfícies de resposta resultantes são ilustradas na Figura 2. 
Tabela 3 - Médias das respostas levantadas experimentalmente

\begin{tabular}{ccccccc}
\hline$X 1$ & $X 2$ & $\eta$ & $Q\left(10^{-6} \mathrm{~m}^{3} / \mathrm{s}\right)$ & $R l$ & $E u$ & $d_{50}^{\prime}\left(10^{-6} \mathrm{~m}\right)$ \\
\hline-1 & -1 & $75,64 \%$ & 202 & $11,17 \%$ & 3185 & 9,61 \\
-1 & 0 & $81,67 \%$ & 213 & $24,95 \%$ & 2869 & 8,30 \\
-1 & 1 & $84,53 \%$ & 225 & $40,20 \%$ & 2568 & 6,61 \\
0 & -1 & $88,58 \%$ & 204 & $12,33 \%$ & 3136 & 7,45 \\
0 & 0 & $90,04 \%$ & 213 & $26,14 \%$ & 2886 & 5,72 \\
0 & 1 & $96,98 \%$ & 221 & $40,54 \%$ & 2664 & 2,24 \\
1 & -1 & $89,39 \%$ & 212 & $13,31 \%$ & 2889 & 7,60 \\
1 & 0 & $94,43 \%$ & 218 & $24,65 \%$ & 2749 & 6,24 \\
1 & 1 & $95,08 \%$ & 229 & $38,25 \%$ & 2492 & 3,64
\end{tabular}

Tabela 4 - Equações das Superfícies de Resposta

\begin{tabular}{ccc}
\hline Variável & Superfície de Resposta & $\mathrm{R}^{2}$ \\
\hline$\eta$ & $\eta=91,87+6,18 X 1+3,83 X 2-5,08 X 1^{2}$ & 0,95 \\
$Q$ & $Q=212,67+3,17 X 1+9,50 X 2+3,83 X 1^{2}$ & 0,96 \\
$R l$ & $R l=25,73+13,70 X 2-1,02 X 1 X 2$ & 0,99 \\
$E u$ & $E u=2895,33-82,00 X 1-247,67 X 2-103,33 X 1^{2}+55,00 X 1 X 2$ & 0,99 \\
$d_{50}^{\prime}$ & $d_{50}^{\prime}=5,14-1,17 X 1-2,03 X 2+1,86 X 1^{2}$ & 0,92
\end{tabular}

De acordo com a Figura 2, pode-se notar que as duas respostas calculadas possuem comportamento não-linear de acordo com a variação de $\ell$ e $D u$, sendo que a superfície de resposta para a eficiência total $(\eta)$ possui ponto de máximo local $(\eta=97,58 \%)$ quando $X 1$ assume o valor igual a $+0,61$ e $X 2$ se encontra no seu limite superior. Já a superfície calculada para a vazão de alimentação possui seu máximo local $\left(Q=229.10^{-6} \mathrm{~m}^{3} / \mathrm{s}\right)$ para os maiores valores de $X 1$ e $X 2$ simultaneamente.
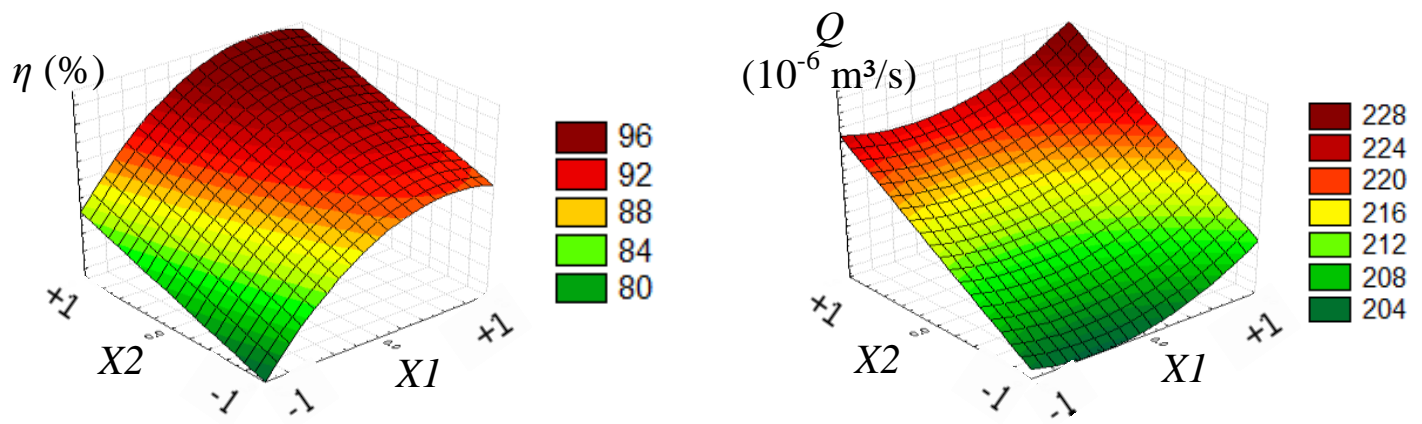

Figura 2 - Superfícies de resposta para Eficiência Total $(\eta)$ e Vazão de Alimentação $(Q)$. 
Com relação às variáveis restantes, as mesmas encontram-se ilustradas nos gráficos da Figura 3. Novamente, todas as respostas foram significativamente afetadas pela variação de $\ell$ e $D u$. A depender do propósito de operação do hidrociclone (classificação ou concentração), pode ser desejável baixos ou altos níveis da variável razão de líquido $(R l)$, ficando a critério do usuário sua melhor escolha. Por outro lado, é desejável que tenha-se sempre o menor custo de operação (menores níveis do número adimensional de Euler), o que acontece para maiores níveis de ambas variáveis, sendo o mínimo local dado por $E u=2492$ em $X 1=X 2=+1,00$. Para clarificar o fluido em suspensão, é recomendável que o diâmetro de corte reduzido $\left(d_{50}^{\prime}\right)$ seja o menor possível. Na região de busca deste trabalho, isso acontece para $X 1$ igual a $+0,31$ e $X 2$ igual a $+1,00$, onde $d_{50}^{\prime}$ alcança seu menor valor $\left(2,93.10^{-6} \mathrm{~m}\right)$.
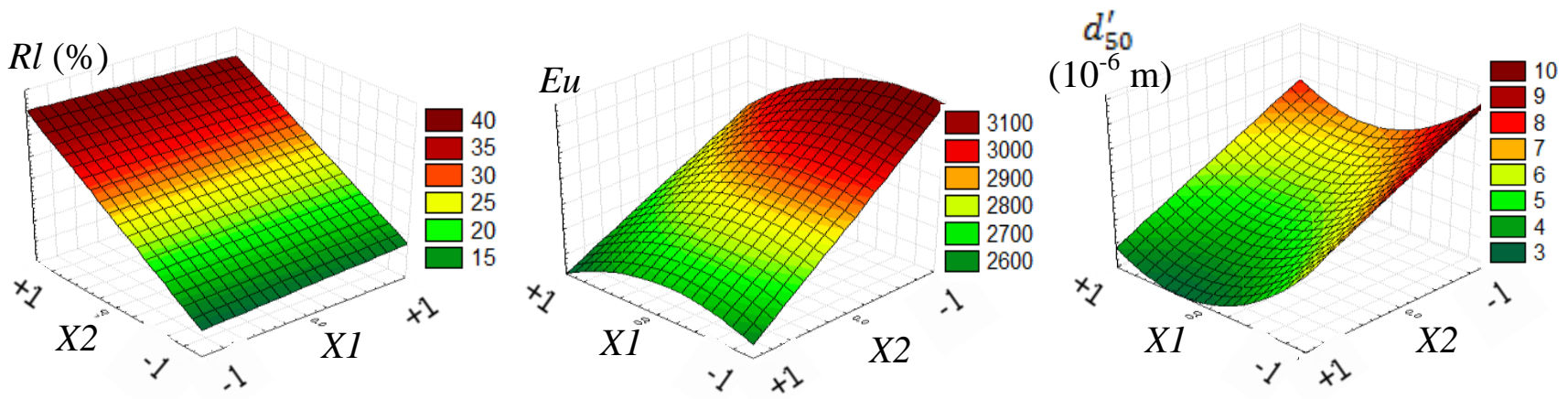

Figura 3 - Superfícies de resposta para Razão de Líquido $(R l)$, Número de Euler $(E u)$ e Diâmetro de Corte Reduzido $\left(d_{50}^{\prime}\right)$.

Ao que concerne os parâmetros " $K$ ”, que especificam as famílias de hidrociclones, para cada

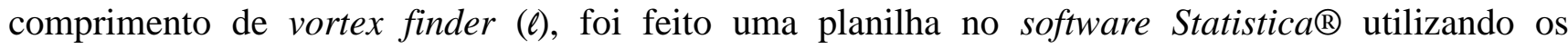
resultados de cada queda de pressão e seus respectivos diâmetros de underflow $(\mathrm{Du})$ empregados. Assim, por meio de ajuste não linear à Equação 12, obteve-se a Tabela 5.

\section{CONCLUSÕES}

Tabela 5 - Valores estimados do parâmetro " $\mathrm{K}$ "

\begin{tabular}{ccc}
\hline$\ell$ & $K$ & $\mathrm{R}^{2}$ \\
\hline $1,00.10^{-3} \mathrm{~m}$ & 0,0472 & 0,91 \\
$6,50 \cdot 10^{-3} \mathrm{~m}$ & 0,1370 & 0,97 \\
$1,20.10^{-2} \mathrm{~m}$ & 0,0772 & 0,95
\end{tabular}

O planejamento experimental variando $\ell$ e $D u$ possibilitou o estudo de 9 hidrociclones diferentes agrupados em 3 distintas famílias, além da estimativa de superfícies de resposta e de constantes representativas de cada família de hidrociclones. Para os dados apresentados, pode-se inferir que o hidrociclone que possui maior eficiência ao menor custo energético aliados à maior capacidade de processamento e menor diâmetro de corte é o hidrociclone que possui $\ell=1,20.10^{-2} \mathrm{~m}$ e $D u=5,00.10^{-3}$ $\mathrm{m}$, o próprio HCOT1. Por outro lado, buscando-se a recuperação do fluido em suspensão, o hidrociclone com $\ell=1,20.10^{-2} \mathrm{~m}$ e $D u=3,00.10^{-3} \mathrm{~m}$ seria o mais indicado, pois dentre os hidrociclones que apresentam baixa razão de líquido, este é o que possui menor número de Euler, maior vazão de alimentação e razoável diâmetro de corte. 


\section{9 a 22 de outubro de 2014 \\ Florianópolis/SC}

\section{NOMENCLATURA}

$A$ - constante característica de uma família de hidrociclones [-]

$C_{V A}$ - concentração volumétrica de sólidos na corrente de alimentação [-]

$C_{V i}$ - concentração volumétrica de sólidos na corrente genérica $i[-]$

$C_{V U}$ - concentração volumétrica de sólidos na corrente de underflow [-]

$C_{W A}$ - concentração mássica de sólidos na corrente de alimentação [-]

$C_{W i}$ - concentração mássica de sólidos na corrente genérica $i[-]$

$C_{W U}$ - concentração mássica de sólidos na corrente de underflow [-]

$d_{50}^{v}$ - diâmetro de corte reduzido [L]

$d_{63,2 A}$ - parâmetro do modelo RRB na

corrente de alimentação [L]

$d_{63,2 U}$ - parâmetro do modelo RRB na corrente de underflow [L]

$d_{p}$ - diâmetro volumétrico da partícula [L]

$D c$ - diâmetro da seção cilíndrica [L]

$D i$ - diâmetro do duto de alimentação [L]

Do - diâmetro do orifício de overflow [L]

$D u$ - diâmetro do orifício de underflow [L]

$E u$ - número de Euler [-]

$G$ - eficiência granulométrica [-]

$G$ ' - eficiência granulométrica reduzida [-]

$K$ - constante característica de uma família de hidrociclones [-]

$\ell$ - comprimento do vortex finder [L]
$L$ - comprimento total do hidrociclone [L]

L1 - comprimento da seção cilíndrica [L]

$n_{A}$ - parâmetro do modelo RRB na corrente de alimentação [-]

$n_{U}$ - parâmetro do modelo RRB na corrente de underflow [-]

$Q$ - vazão volumétrica de suspensão na corrente de alimentação $\left[\mathrm{L}^{3} \mathrm{~T}^{-1}\right]$

$Q_{i}$ - vazão volumétrica de suspensão na corrente genérica $i\left[\mathrm{~L}^{3} \mathrm{~T}^{-1}\right]$

$Q_{U}$ - vazão volumétrica de suspensão na corrente de underflow $\left[\mathrm{L}^{3} \mathrm{~T}^{-1}\right]$

$R l$ - razão de líquido [-]

$X$ - fração mássica de partículas na corrente de alimentação com diâmetro igual/inferior a $\mathrm{d}_{\mathrm{p}}[-]$

$X_{u}$ - fração mássica de partículas na corrente de underflow com diâmetro igual/inferior a $\mathrm{d}_{\mathrm{p}}[-]$

$X 1$ - variável codificada 1 representativa de $\ell[-]$

$X 2$ - variável codificada 2 representativa $D u[-]$

$W$ - vazão mássica corrente de aliment. $\left[\mathrm{MT}^{-1}\right]$

$W_{i}$ - vazão mássica corrente genérica $i\left[\mathrm{MT}^{-1}\right]$

$W_{U}$ - vazão mássica corrente underflow $\left[\mathrm{MT}^{-1}\right]$

$(-\Delta P)$ - queda de pressão $\left[\mathrm{ML}^{-1} \mathrm{~T}^{-2}\right]$

$\eta$ - eficiência total de separação [-]

$\mu$ - viscosidade dinâmica do fluido $\left[\mathrm{ML}^{-1} \mathrm{~T}^{-1}\right]$

$\theta$ - ângulo de abertura da parte cônica $\left[{ }^{\circ}\right]$

$\rho$ - densidade do líquido $\left[\mathrm{ML}^{-3}\right]$

$\rho_{i}$ - densidade da corrente genérica $i\left[\mathrm{ML}^{-3}\right]$

$\rho_{s}-$ densidade do sólido $\left[\mathrm{ML}^{-3}\right]$

\section{AGRADECIMENTOS}

Os autores do trabalho agradecem à CAPES, FAPEMIG (PCE-00082/14) e ao LASER/FEQUI.

\section{REFERÊNCIAS}

MASSARANI, G. Projeto e análise do desempenho de ciclones e hidrociclones ii. In: Anais do XVII Encontro Nac. sobre Escoam. em Meios Porosos, [S.1.: s.n.], p. 125-136, São Carlos, 1989.

SILVA, D. O. Hidrociclones: Um Estudo de Otimização e Análise do Efeito das Variáveis Geométricas Utilizando Técnicas Experimentais e de CFD. 185 f. Tese de Doutorado em Engenharia Química - PPGEQ, Universidade Federal de Uberlândia, Uberlândia, 2012.

VIEIRA, L. G. M. Otimização dos Processos de Separação em Hidrociclones Filtrantes. Tese de Doutorado em Engenharia Química - PPGEQ, Universidade Federal de Uberlândia, 297 p., 2006. 